\title{
Monoclonal antibodies in diagnosis and treatment
}

The ability to produce monoclonal antibodies of defined antigenic specificity in unlimited quantities represents a milestone in immunological research. Conventional polyclonal antisera are produced by repeated immunisation of animals such as rabbits, sheep, or goats. These antisera contain mixtures of antibodies with differing specificities, and to obtain antisera of a defined antigenic specificity several absorption steps are usually necessary. In 1975 Kohler and Milstein ${ }^{1}$ fused primed B cells from immunised mice with an immortal myeloma cell line of the same species, and after selective cloning produced monoclonal antibodies to that antigen in unlimited quantities. The myeloma cell line was originally grown in selective media so that the cells became deficient in the purine enzyme hypoxanthine guanine phosphoribosyltransferase (HGPRTthe enzyme deficiency of Lesch-Nyhan syndrome) ${ }^{2}$ These lines, if grown in media containing hypoxanthine, aminopterin, and thymidine, will not survive but if the enzyme is supplied by the fused normal B cell partner, then the fused cells have a selective advantage. Theoretically any antigen of interest can be used for immunisation and, in fact, monoclonal antibodies to cell surface glycoproteins, enzymes, drugs, bacterial cell surfaces, and virus components have all been raised. These monoclonal antibodies have made an enormous impact on research and diagnosis in all aspects of laboratory medicine and hold considerable therapeutic potential.

\section{Uses in diagnosis}

The development of monoclonal antibodies to leucocyte differentiation antigens and in particular to lymphocyte subpopulations has provided considerable research interest. Monoclonal antibodies which react with different $T$ cell antigens are now available, including the $\mathrm{E}$ rosette receptor (T11), most mature $T$ cells (T3), helper/inducer $T$ cells (T4), and the suppressor/cytotoxic T cell subpopulation (T8) ${ }^{3}$ Similarly there are monoclonal antibodies directed against $\mathrm{B}$ cells, natural killer cells, granulocytes, monocytes, eosinophils, platelets, and megakaryocytes. As these monoclonal reagents have defined functional subpopulations of cells, our understanding of the network involved in the immune response is rapidly increasing. Furthermore, the relation of these $T$ cell subpopulations in various primary immune deficiency syndromes and in diseases of immune dysregulation, for example autoimmunity or acquired immune deficiency syndromes, have been characterised. An area of particular interest to paediatricians is the ability to perform prenatal diagnosis for severe combined immune deficiency using these monoclonal antibodies. ${ }^{4}$ Bruton's X-linked agammaglobulinaemia should also be capable of similar prenatal diagnosis, as should the syndrome of delayed cord separation, neutrophil mobility deficiency in association with gamma interferon deficiency, ${ }^{5}$ as it has recently been shown that patients with this disease lack a cell surface protein glycoprotein on leucocytes, recognised by monoclonal antibodies OKM1 and LFA1. ${ }^{6}$ There have been many published reports on the helper/inducer to suppressor/cytotoxic $\mathrm{T}$ lymphocyte ratio (T4/8) in disease. In autoimmunity there seems to be a lack of suppressor cells, both in terms of number and function, and a hallmark of the acquired immune deficiency syndrome (AIDS) is a reversal of the normal T4:T8 ratio $^{7}$ (2:1 in normal children).

Several antibodies have been described which react with progenitor cells and these have been used as an aid in the diagnosis of different leukaemias. The J5 antibody ${ }^{8}$ recognises the common acute lymphoblastic leukaemia. This acute lymphoblastic leukaemia antigen is not specific for leukaemic cells as a small population of positive cells are found in normal bone marrow and other tissues. In fact, so far all antibodies raised against malignant cells show apparent specificity for the malignant cells, but invariably react with a small population of cells in normal tissues.

Diagnostic uncertainty often results when conventional histological staining techniques are applied to the variety of solid tumours which occur in childhood. Neuroblastoma and lymphoma cells may all have the appearance of small round cell tumours and be indistinguishable morphologically. Monoclonal antibodies which react predominantly with the tumour type, that is those raised to neural crest cells and which react with neuroblastoma cells have proved particularly useful in differentiating between these tumours. ${ }^{9}$ A panel of monoclonal antibodies directed at different cell types may be used for such diagnostic distinction.

Monoclonal antibodies directed at bacterial, viral, or fungal antigens are proving invaluable in the rapid diagnosis of a variety of infections. Simple screening tests using antibody coated to latex particles which agglutinate in the presence of the 
antigen or enzyme linked immunosorbent assays (ELISA) are commercially available for a number of antigens. Rapid diagnosis of meningococcal, pneumococcal, and haemophilus meningitis may be made using these techniques and kits are available for the rapid detection of hepatitis B antigen. ${ }^{10}$ It is probable that in time a wide battery of monoclonal antibodies will be available for rapid diagnosis of bacterial and viral infections. Since monoclonal antibodies have such a uniquely defined specificity, recognising only a small area of the whole antigen (this is known as an epitope), these antisera can be used for serotypic analysis of different strains of bacteria and viruses.

In the field of endocrinology, monoclonal antibodies provide unlimited supplies of reagents for interlaboratory comparison of assays for different hormones. Similarly enzyme activities may be detected by immunoassays using monoclonal antibodies.

All these techniques rely on in vitro biological assay systems, but monoclonal antibodies have also been used for in vivo diagnosis. Antibodies reacting against tumours when coupled to a radio label may be used for radioisotope scanning and small metastasis may be visualised in this way. There are still considerable problems with this technique since much of the injected monoclonal antibody may be non-specifically taken up by the reticuloendothelial system. Attempts to remove the Fc part of the molecule and so prevent the reticuloendothelial system uptake have not as yet been successful and some form of modification of this part of the immunoglobulin molecule will be necessary before the technique can become widely available. Using subtraction techniques, however, localisation of tumours, and in particular small secondaries, is still possible. ${ }^{11}$

\section{Uses in treatment}

The most attractive, prospective in vivo use of highly specific monoclonal antibodies would be as carriers to target treatment (drugs or radioactivity) to pathological tumours, by bearing the relevant tumour antigens and thereby sparing the normal tissues. With this in mind the term 'magic bullet' has been coined, but several problems will need to be overcome before this prospect is realised. Firstly, antibodies will need to be raised with precise tumour specificity; secondly, the problem of bypassing uptake by the reticuloendothelial system will need to be overcome; and thirdly, it is not possible to inject these foreign mouse proteins repeatedly into man since an immune response is elicited after two or three injections resulting in too rapid clearance of the monoclonal antibody. In preliminary studies, treatment with antidigitalis monoclonal antibodies has proved effective in patients poisoned by digoxin. ${ }^{12}$ In addition, initial immunosuppression after organ transplantation has been achieved using anti-T lymphocyte monoclonal antibodies, and kidney allograft rejection crises have been successfully managed by infusing these antibodies into the recipient. ${ }^{13}$ This type of treatment, however, is limited to a very short course before man develops anti-mouse antibodies in sufficient quantities to render the procedure ineffective. Where patients are already immunosuppressed, however, treatment with monoclonal antibodies may be continued for longer periods before an immune response is evoked.

There is enormous research interest in coupling tumour specific monoclonal antibodies to poisons and drugs of various types. One of the most potent cell poisons available is the $\alpha$-chain of ricin, and this may be coupled to a monoclonal antibody so producing a highly selective cell poison. This has, however, been limited to in vitro use as no one has been courageous enough to inject such preparations into man. Indeed, it is in the in vitro depletion of a population of cells in bone marrow where monoclonal antibodies have been particularly useful. In bone marrow transplantation one of the biggest problems is the elimination of graft versus host disease, and more than this the inability to transplant across histocompatibility barriers, that is from parent to child. Techniques for doing this are now available by selectively depleting the donor bone marrow of all immunocompetent T cells. A recently published report from the Royal Free Hospital ${ }^{14}$ has shown that the incidence of graft versus host disease in HLA-matched leukaemic patients was dramatically reduced by selective $\mathrm{T}$ cell depletion using a 'cocktail' of anti-T cell monoclonals. Similarly, transplantation across histocompatibility barriers has been achieved in children with severe combined immune deficiency by $\mathrm{T}$ cell depletion with a rat monoclonal antibody Campath I and complement lysis. ${ }^{15}$ Such $\mathrm{T}$ cell depleted bone marrow contains sufficient stem cells to repopulate the recipient bone marrow and the immune system which subsequently develops no longer recognises the host as foreign (a phenomenon known as tolerance).

One limitation of the treatment of children with extensive malignancy is that of bone marrow toxicity to cytotoxic drugs. A strategy which has been developed is that of collecting autologous bone marrow before administration of lethal chemotherapy and then rescuing the patient by giving back the autologous marrow. In extensive disease where the marrow is affected, however, small amounts of 
tumour cells may be present in the reinfused marrow and recently techniques have been developed to 'clean up' these marrows using monoclonal antibodies specific for the tumour. One such technique used for the treatment of neuroblastoma has been to couple monoclonal antibodies to magnetic beads and then remove the tumour cells with powerful magnets. ${ }^{16}$

\section{Future potential}

The production of these antibodies in species such as mice or rats has produced an unlimited supply of identical reagents allowing interlaboratory comparison of diagnostic procedures throughout the world. Therapeutically their uses are of less value since they are still foreign proteins and cannot be used extensively in vivo. They are proving invaluable, however, in the manipulation of bone marrow in vitro. As in vivo tools, the next step is to produce monoclonal antibodies of human origin and this has already been achieved for certain antigens, for example rhesus $D$ antisera for the prevention of rhesus isoimmunisation. ${ }^{17}$ Considerable research is being expended on the production of human monoclonals to bacteria and viruses as antidotes to a variety of infectious diseases and it is hoped that specific antibodies will be produced in large quantities in the future. Similarly, in time, human monoclonals with specificities to tumour antigens may be produced and these would be immensely powerful tools in the in vivo diagnosis of small malignancies and also in the selective treatment of these tumours.

GM is supported by the Lee Smith Research Foundation and RJL by the Leukaemia Research Fund.

\footnotetext{
References

1 Kohler G, Milstein C. Continuous cultures of fused cells secreting antibody at predefined specificity. Nature 1975;256: 495-7.

2 Seegmuller JE, Rosenbloom FM, Kelley WN. Enzyme defect associated with a sex-linked human neurological disorder and excessive purine synthesis. Science 1967;155:1682-4.

${ }^{3}$ Reinherz EL, Schlossman SF. The characterization and function
}

of human immunoregulatory T-lymphocyte subsets. Immunology Today 1981;2:69-75.

4 Linch DC. Levinsky RJ. Prenatal diagnosis of fetal immunological disorders. Br Med Bull 1983;39:399-404.

5 Davies EG, Isaacs D, Levinsky RJ. A lethal syndrome of impaired neutrophil mobility and absent natural killer activity associated with delayed umbilical cord separation. Clin Exp Immunol 1982;50:454-60.

${ }^{6}$ Seger R, Fischer A, Durandy A, et al. Adhesive protein deficiency resulting in abnormal phagocytic cell functions and impaired cytotoxicity. In: Griscelli C, Vossen J, eds. Progress in immunodeficiency research and therapy 1. Amsterdam: Exerpta Medica, 1984:83-92.

${ }^{7}$ Gottlieb MD, Schraff R, Howard, M, et al. Pneumocystis pneumonia and mucosal candidiasis in previously healthy homosexual men. $N$ Engl J Med 1981;305:1425-31.

${ }^{8}$ Ritz J, Pesando JM, Notis-McConarty J, et al. A monoclonal antibody to human acute lymphoblastic leukaemia antigen. Nature 1980;283:583-5.

${ }^{9}$ Kemshead JT, Goldman A, Fritschy J, et al. Use of panels of monoclonal antibodies in the differential diagnosis of neuroblastoma and lymphoblastic disorders. Lancet 1983;i:12-4.

10 Wands JR, Marciniak RA, Isselbacher KJ, et al. Demonstration of previously undetected hepatitis B viral determants in an Australian aboriginal population by monoclonal anti-HBs antibody radioimmunoassays. Lancet 1982;i:977-80.

" Farrands PA, Perkins AC, Pimm MV. Radioimmunodetection of human colorectal cancers by an anti-tumour monoclonal antibody. Lancet 1982;ii:397-400.

12 Smith TW, Butler VP, Haber E, et al. Treatment of lifethreatening digitalis intoxication with digoxin-specific Fab antibody fragments. $N$ Engl $J$ Med 1982;307:1357-62.

13 Cosimi AB, Colvin RB, Burton RC, et al. Use of monoclonal antibodies to T-cell subsets for immunologic monitoring and treatment in recipients of renal allografts. $N$ Engl $J$ Med 1981;305:308-14.

14 Prentice HG, Blacklock HA, Janossy G, et al. Depletion of Tlymphocytes in donor marrow prevents significant graft-versushost disease in matched allogenic leukaemic marrow transplant recipients. Lancet 1984;i:472-6.

15 Levinsky RJ, Morgan G, Davies EG, et al. Mismatched bone marrow transplantation for severe combined immunodeficiency. In: Griscelli C, Vossen J, eds. Progress in immunodeficiency research and therapy 1. Amsterdam: Excerpta Medica, 1984:393-9.

16 Treleaven JG, Gibson FM, Ugelstad J, et al. Removal of neuroblastoma cells from bone marrow with monoclonal antibodies conjugated to magnetic microspheres. Lancet 1984;i: 70-3.

17 Crawford DH, Barlow MJ, Harrison JF, et al. Production of human monoclonal antibody to rhesus $\mathrm{D}$ antigen. Lancet 1983;i:386-8.

G Morgan AND R J Levinsky Institute of Child Health, London, WCI IEH 